University of Washington Tacoma

UW Tacoma Digital Commons

Social Work \& Criminal Justice Publications

Social Work \& Criminal Justice

$5-2006$

\title{
A Comparison of HIV Stigma and Disclosure Patterns Between Older and Younger Adults Living With HIV/AIDS
}

Charles Emlet

University of Washington Tacoma, caemlet@uw.edu

Follow this and additional works at: https://digitalcommons.tacoma.uw.edu/socialwork_pub

Part of the Social Work Commons

\section{Recommended Citation}

Emlet, Charles, "A Comparison of HIV Stigma and Disclosure Patterns Between Older and Younger Adults Living With HIV/AIDS" (2006). Social Work \& Criminal Justice Publications. 5.

https://digitalcommons.tacoma.uw.edu/socialwork_pub/5 


\title{
A Comparison of HIV Stigma and Disclosure Patterns Between Older and Younger Adults Living with HIV / AIDS
}

\author{
CHARLES A. EMLET, Ph.D., M.S.W.
}

\begin{abstract}
The purpose of this study was to examine the relationships between age, HIV-related stigma, and patterns of disclosure. Previous literature has suggested that older age is associated with increased HIV stigma and less disclosure of HIV status. Eighty-eight individuals, 44 between the ages of 20-39 and 44 aged 50 and over were recruited for the study through an AIDS service organization in the Pacific Northwest. Subjects in each group were matched as closely as possible by gender, ethnicity, HIV exposure and diagnosis. In a comparison of sociodemographic characteristics, older adults $(50+)$ were significantly more likely to live alone, and to be retired. Younger adults were significantly more likely to be never married/ partnered, unemployed and be recipients of Medicaid. Bivariate analysis revealed no significant differences in overall stigma scores between groups; however, younger adults were more likely to fear losing their job because of HIV. Older adults were less likely to disclose HIV to relatives, partners, mental health workers, neighbors, and church members than those 20-39 years of age. Pearson product moment correlations found disclosure to be significantly associated with time since diagnosis, heterosexual exposure, ethnicity, use of HIV services, and having a confidant. Stigma was associated with ethnicity, having a confidant, and instrumental social support. In a multiple regressions analysis, $48.4 \%$ of the variance in disclosure accounted for by time since first diagnosis, service use, and having a confidant. Service use was the only independent variable significantly associated with stigma, accounting for $21.6 \%$ of the variance.
\end{abstract}

\section{INTRODUCTION}

$\mathbf{T}$ WO IMPORTANT AND INTERRELATED phenomenon for people living with HIV / AIDS are stigma and disclosure of HIV status. HIV stigma is a ubiquitous phenomenon that the Joint United Nations Programme on HIV/ AIDS (UNAIDS) suggests is "universal, occurring in every county and region of the world." ${ }^{1}$
UNAIDS has well-documented cases from throughout the world of persons being stigmatized and discriminated against and denied services due to their serostatus. ${ }^{2}$ Based on the work of Goffman, ${ }^{3}$ HIV-related stigma has been defined as prejudice, discounting, discrediting, and discrimination that are directed at people perceived to have HIV or AIDS. ${ }^{4}$ Numerous studies have found HIV stigma to

Social Work Program, University of Washington, Tacoma, Tacoma, Washington. 
be associated with various interpersonal and psychosocial issues such as feelings of shame, guilt, fear and anger, ${ }^{5,6}$ mental strain, ${ }^{7}$ and feelings of self loathing. ${ }^{2,3,8} \mathrm{HIV}$ stigma has also been associated with clinical symptoms of depression and initiation and continuation of antiretroviral therapy in a variety of HIV infected populations. $3,9-13$

Disclosure of HIV status is a closely related construct. Through disclosure of HIV, the seropositive person may reduce potential infections of sexual partners thereby diminishing the spread of HIV. ${ }^{14}$ Disclosure also provides a means for obtaining social support to assist in coping with the disease process. ${ }^{15}$ Conversly, disclosure of HIV status open up the potential for stigma and the shame of having $\mathrm{HIV}^{16}$ and the experience of disclosing has been documented as traumatic. ${ }^{17}$ Nondisclosure can also be a means of "protective silence."18 By limiting the disclosure of one's HIV status, the possibility of facing stigma and discrimination is thereby controlled. As Shehan and colleagues ${ }^{19}$ have suggested, the power of the stigma associated with HIV may override the need for support.

Although we have gained considerable ground in understanding stigma and disclosure among younger people living with HIV/ AIDS, this is less true for older adults. Understanding potential differences among age groups is critical when we consider the growing number of persons age 50 and over who are living with HIV/AIDS. A recent analysis of data from the Centers for Disease Control (CDC) shows that the cumulative number of AIDS cases reported in adults $50+$ years had quintupled between 1990 and 2001, ${ }^{20}$ and that the estimated number of persons age 55 and over living with HIV / AIDS in the United States increased from 18,581 in 2000 to 31,947 by 2003. ${ }^{21}$ Between 1994 and 2000, the number of adults living with AIDS in the 65-69 and 70 and older age groups more than tripled. ${ }^{22}$

The advent of highly active antiretroviral therapies (HAART) in the 1990s has extended life for many persons with HIV disease and will allow, as never before, individuals who were infected in middle age to live into "old age." These recent trends have created two distinct populations of older persons with HIV/AIDS; those who where infected later in life and those infected earlier and now aging with HIV disease. As increasing numbers of older adults with HIV live longer lives, it is incumbent upon AIDS service providers and the health care system in general, to better understand the factors that contribute, either positively or negatively to their quality of life.

Despite the growing number of older adults living with HIV / AIDS, our knowledge of HIV stigma and disclosure among this population is extremely limited. This is likely resulting from the fact that numerous studies examining stigma and/or disclosure have: (1) not included older persons; (2) eliminated older persons from the analysis, or; (3) not considered age as a variable in the analysis of data. The purpose of this study, therefore, is to examine the extent to which older adults may differ in their experiences of HIV-related stigma and disclosure patterns as compared to younger persons.

\section{Stigma and disclosure in older adults}

Anecdotal reports and case studies have suggested that older adults face increased risk of HIV stigma compared to their younger counterparts. ${ }^{23-26}$ Solomon $^{24}$ suggests that older adults may experience stigma more intensely than younger adults because their contemporaries continue to judge behaviors related to HIV risk as morally wrong. There is support for this position, because recent research suggests that older persons in the general public are more likely to posses stigmatizing beliefs related to HIV than younger adults. ${ }^{27}$ For example data from the CDC found adults age 55-64 and 65+ to have the highest proportion of respondents $(21.9 \%$ and $35.2 \%$, respectively) agreeing with the statement "people who get AIDS through sex or drug use have gotten what they deserve." 28 Older adults may feel stigmatized when, after diagnosis, it becomes necessary to disclose their diagnosis and sexual orientation to adult children. ${ }^{23}$ Overall, however, the position of increased stigma with age has been difficult to substantiate as a review of the literature reveals a paucity of stigma related research including older adults. For example, in studies of HIV stigma done by numerous re- 
searchers, older adults were not included. ${ }^{2-4}$ Studies that have recruited older persons have, in some instances, eliminated them from the analysis because they were viewed as outliers in the distribution of the sample. ${ }^{29}$ In a study of stigma and shame among individuals recently tested for HIV or gonorrhea, all individuals over 59 years of age were eliminated from the analysis in order to "focus on the groups at greatest STD/HIV risk." 30 Still other studies on HIV stigma have not included age as a variable in the analysis. ${ }^{31,32}$ Lee and colleagues $^{33}$ studies internalized HIV stigma in 268 men and women, including older adults from ages 50 to 60.5 in their research. They found no significant difference in age between those with high and low levels of internalized stigma. In one of the few studies examining HIV-related stigma exclusively in those age 50 and over, Heckman et al. ${ }^{11}$ studies 83 persons over 50 with HIV disease. Stigma was included in this study that focused on depression and quality of life. HIV stigma was associated with cognitive affective symptoms of depression and increased barriers to health care. Because all participants in the study were $50+$ years, no comparison of stigma between age groups was possible. While not addressing stigma directly, Pitts and colleagues ${ }^{34}$ found adults 50 and over to have significantly lower levels of well-being and less likely to feel positive about themselves as their younger counterparts.

Our knowledge concerning age and disclosure of HIV status is virtually undeveloped. Two recent studies in which disclosure patterns were examined by age present differing results. In a national sample of 713 HIV-infected individuals, Nokes and colleagues ${ }^{35}$ found persons 50 and over to have disclosed their HIV status to significantly fewer persons than their younger counterparts. In a study of HIV-positive men and casual sexual partners, Serovich and Mosack ${ }^{14}$ found that age did not influence whether a respondent disclosed the status to all, some or none of their sexual partners. While age was included in their analysis, there was no specific exploration of disclosure practices between younger and older men. Shehan and colleagues ${ }^{19}$ studied 166 HIV-seropositive men ages $20-70$ and the patterns of disclosure to their mothers. They found older men signifi- cantly less likely than younger men to inform their mother. It is possible, however that men age 50 and over are less likely to have living mothers. Other studies focusing on disclosure have not identified age as a variable for analysis in the research. ${ }^{14,36-38}$

In order to move our knowledge related to HIV / AIDS among older adults forward, older persons must be actively recruited and included in relevant research. This need is particularly true with regards to the topics of HIVrelated stigma and disclosure.

\section{MATERIALS AND METHODS}

\section{Participants and procedures}

Interviews of all participants were conducted during 2002/2003 in collaboration with an AIDS service organization (ASO) in the Pacific Northwest. According to agency data, $12.3 \%$ of unduplicated clients from this agency were age 50 and over, approximating the percentage of older adults living with AIDS found in national statistics as well as in Washington State. As part of the cooperative research agreement, case managers from the ASO contacted clients (both active and inactive) in the agency database who were 50 years of age or older, notifying them of the opportunity to participate in this study. Because of the relatively small number of individuals age 50 and over living with HIV disease, purposive sampling techniques were used. A comparison sample was developed using a matched case control design. Each older adult was matched, as closely as possible, on gender, ethnicity, HIV transmission route and diagnosis with an individual between the ages of 20 and 39 years. During the initial contact with respondents, the study was briefly described; for those interested, an appointment was made for a face-to-face interview with the principal investigator or a research assistant. At that initial appointment, the study was described in detail, and participants who wished to continue signed the informed consent. Structured interviews lasted 45 minutes to 1 hour. All procedures were approved by the university Institutional Review Board. 


\section{Measures}

During the interview, participants answered questions related to sociodemographic characteristics including age, gender, race and ethnicity, education, income, employment status, Medicaid eligibility and HIV diagnosis (HIV versus AIDS). In addition to this information, participants completed an HIV stigma questionnaire as well as a disclosure inventory. The 13-item stigma scale was developed by Sowell and colleagues ${ }^{39}$ and was designed to measure the phenomenon of HIV-stigma. The instrument utilizes a four-point Likert type scale ranging from 1 to 4 (1 being "not at all" and 4 equaling "often"). The measure was designed to determine how often individuals had thoughts and feelings of being stigmatized or put in jeopardy as a result of their illness. The measure provides a summated score ranging from 13 to 52 . The scale showed good internal consistence in this study $(\alpha=0.830)$.

The disclosure inventory asked individuals if they had disclosed their HIV status to 15 categories of individuals ranging from spouses/ lovers to physicians, nurses or mental health professionals. Answers were coded " 1 " if they had disclosed to someone in that category and " 0 " if they had not disclosed. The inventory was summed indicating the total number of types of persons their HIV status had been disclosed to. In addition to stigma and disclosure instruments, participants completed the Lubben Social Network Scale, 18 -item version. This scale asks respondents to identify the quantity of individuals in each of three categories: friends, relatives and neighbors as well as the frequency of contact and the number of individuals one should call on for help and talk to about private matters. The 18 -item version has been shown to have good internal consistency $(\alpha=0.82) .{ }^{40}$

\section{RESULTS}

\section{Sample characteristics}

The final sample consisted of 88 individuals, divided into 2 age groups. Forty-four individuals ranged in age from 50 to 71 years of age with a mean of 55.45 (standard deviation [SD],
5.40). The younger comparison group ranged from 21-39 years of age with an average of 34.66 (SD, 4.0). Table 1 provides of a comparative profile of the study participants by sociodemographic characteristics.

Because of comparison group matching, the samples differed little by race, ethnicity, and gender. As seen in Table 1, those over 50 were significantly more likely to live alone than their younger counterparts $\chi^{2}(2, n=88)=9.14, p<$ 0.01 . The younger group was more likely to be never married than older adults $\chi^{2}(2, n=$ $88)=8.44, p<0.05$. Both groups had average educational levels slightly higher than the completion of high school. While similar proportions of both populations were working either full or part time, those over 50, not surprisingly, were more likely to indicate they were retired

\begin{tabular}{|c|c|c|}
\hline \multirow[b]{2}{*}{ Variable } & \multicolumn{2}{|c|}{ Population } \\
\hline & $\begin{array}{c}20-39 \text { years } \\
(\mathrm{n}=44)\end{array}$ & $\begin{array}{c}50+\text { years } \\
(\mathrm{n}=44)\end{array}$ \\
\hline Mean age (SD) & $34.6(4.05)$ & $55.4(5.40)$ \\
\hline Male & 50.8 & 49.2 \\
\hline White & 70.5 & 70.5 \\
\hline African American & 20.5 & 20.5 \\
\hline Hispanic & 6.8 & 6.8 \\
\hline Other & 2.3 & 2.3 \\
\hline \multicolumn{3}{|l|}{ Living arrangement** } \\
\hline Lives alone & 18.2 & 47.7 \\
\hline With family or partner & 61.4 & 43.2 \\
\hline Other & 20.5 & 9.1 \\
\hline \multicolumn{3}{|l|}{ Marital/partner status* } \\
\hline Never married & 38.6 & 20.5 \\
\hline Partnered & 38.6 & 27.3 \\
\hline Other & 22.7 & 52.3 \\
\hline Education & 12.1 & 13.1 \\
\hline \multicolumn{3}{|l|}{ Current employment*** } \\
\hline Unemployed & 75.0 & 23.3 \\
\hline Retired & 6.8 & 51.2 \\
\hline Works PT/FT & 18.2 & 25.6 \\
\hline Medicaid* & 77.3 & 52.3 \\
\hline \multicolumn{3}{|l|}{ HIV exposure } \\
\hline MSM & 50.0 & 38.6 \\
\hline Hetero & 36.4 & 43.2 \\
\hline IDU & 11.4 & 11.4 \\
\hline Other & 2.3 & 6.8 \\
\hline HIV & 25.9 & 29.3 \\
\hline AIDS & 74.1 & 70.7 \\
\hline
\end{tabular}

${ }^{*} p<0.05 ;{ }^{* *} p<0.01 ;{ }^{* * *} p<0.001$.

$\mathrm{SD}$, standard deviation; PT, part time; FT, full time; MSM, men who have sex with men; Hetero, heterosexual; IDU, injection drug use. 
due either to disability or age. Those in the 20-39 age group were more likely to be unemployed $\chi^{2}(2, n=87)=27.20, p<0.001$. Those in the 20-39 age group were also more likely to have been on Medicaid in the past 12 months than their older counterparts $\chi^{2}(1, n=88)=$ 6.02, $p<0.05$. Because of the matched case method, little differences existed in either HIV exposure or HIV versus AIDS diagnosis.

\section{Analysis of stigma}

The distribution of scores on the HIV stigma scale across age groups in shown in Table 2. What quickly becomes evident from these data is that differences between age groups are minimal. The only difference between groups that reached statistical significance is the question related to losing one's job. Here, those 20-39 years were significantly more concerned about losing their job if their employer found out about their HIV status $\chi^{2}(3, n=88)=16.55$, $p<0.001$, despite the fact that the younger group was not significantly more likely to be employed than those adults $50+$.

What is perhaps as important about these findings as between group differences, is the extent to which these individuals, regardless of age, experience HIV-related stigma. For example, 50 percent of older persons and $45.5 \%$ of

Table 2. Distribution of Stigma Scores by Age Group

\begin{tabular}{|c|c|c|c|c|}
\hline Question & Not at all & Rarely & Sometimes & Often \\
\hline \multicolumn{5}{|c|}{ I feel blamed by others for my illness } \\
\hline $20-39$ & 62.2 & 11.4 & 13.6 & 6.8 \\
\hline $50+$ & 63.6 & 9.1 & 20.5 & 6.8 \\
\hline \multicolumn{5}{|c|}{ I feel ashamed of my illness } \\
\hline 20-39 & 36.4 & 18.2 & 18.2 & 27.3 \\
\hline $50+$ & 38.6 & 11.4 & 22.7 & 27.3 \\
\hline \multicolumn{5}{|c|}{ I feel my illness is a punishment } \\
\hline $20-39$ & 52.3 & 6.8 & 20.5 & 20.5 \\
\hline $50+$ & 59.1 & 13.6 & 11.4 & 15.9 \\
\hline \multicolumn{5}{|c|}{ Lose my job } \\
\hline $20-39$ & 47.7 & & 11.4 & 40.9 \\
\hline $50+$ & 70.5 & 13.6 & 4.5 & 11.4 \\
\hline \multicolumn{5}{|c|}{ Avoid me } \\
\hline 20-39 & 43.2 & 20.5 & 18.2 & 18.2 \\
\hline $50+$ & 50.0 & 15.9 & 20.5 & 13.6 \\
\hline \multicolumn{5}{|c|}{ Lose friends } \\
\hline 20-39 & 56.8 & 9.1 & 11.4 & 22.7 \\
\hline $50+$ & 51.1 & 9.1 & 17.0 & 22.7 \\
\hline \multicolumn{5}{|c|}{ Family reject me } \\
\hline $20-39$ & 68.2 & 11.4 & 6.8 & 13.6 \\
\hline $50+$ & 70.5 & 2.3 & 20.5 & 6.8 \\
\hline \multicolumn{5}{|c|}{ Poorer health care } \\
\hline 20-39 & 70.5 & 9.1 & 9.1 & 11.4 \\
\hline $50+$ & 61.4 & 13.6 & 20.5 & 4.5 \\
\hline \multicolumn{5}{|c|}{ Change my residence } \\
\hline 20-39 & 63.6 & 6.8 & 13.6 & 15.9 \\
\hline $50+$ & 84.1 & 4.5 & 2.3 & 9.1 \\
\hline \multicolumn{5}{|c|}{ Avoid treatment } \\
\hline 20-39 & 77.3 & 9.1 & 9.1 & 4.4 \\
\hline $50+$ & 88.6 & 2.3 & 6.8 & 2.3 \\
\hline \multicolumn{5}{|c|}{ Hurt family } \\
\hline $20-39$ & 77.3 & 9.1 & 9.1 & 4.4 \\
\hline $50+$ & 88.6 & 2.3 & 6.8 & 2.3 \\
\hline \multicolumn{5}{|c|}{ Uncomfortable with me } \\
\hline 20-39 & 20.5 & 22.7 & 36.4 & 20.5 \\
\hline $50+$ & 27.3 & 22.7 & 31.8 & 18.2 \\
\hline \multicolumn{5}{|c|}{ Kid gloves } \\
\hline $20-39$ & 54.5 & 4.5 & 22.7 & 18.2 \\
\hline $50+$ & 59.1 & 18.2 & 15.9 & 6.8 \\
\hline
\end{tabular}


those 20-39 stated they felt ashamed of their illness "sometimes" or "often." Over 30\% of both age groups felt that people avoid them due to their illness "sometimes" or "often." Fifty percent or more of respondents from both groups felt that people were uncomfortable being with them due to their HIV. Total stigma scores which could range from 13 to 52, differed little across groups. Those 50 and over had a mean stigma score of 23.02 compared to 25.18 in the younger comparison group. While scores for the younger group were slightly higher, these differences did not reach statistical significance.

Differences in stigma scores analyzed by sociodemographic variables found few differences. Few differences exist because of gender, HIV risk groups, education, or income level (as measured by Medicaid eligibility). Ethnicity appears to be an important consideration because African Americans had significantly higher overall mean stigma scores than their white counterparts. The mean stigma score for whites was 22.63 while African American respondents had a mean score of 27.83 and others 27.13 $F(d f 87)=2.85, p<0.001$.

\section{Analysis of disclosure}

The examination of HIV disclosure patters across age groups was also conducted. Overall, the disclosure patterns of younger and older individuals were quite similar. Older adults were significantly more likely to disclose their HIV status to their children, $57.9 \%$ versus $31.8 \%$ re- spectively $(p<0.05)$, however, it is possible they are more likely to have biologic children than members of the younger group. While rarely reaching the level of statistical significance, an overall pattern that emerges is the tendency for older adults to disclose less frequently than their younger counterparts. Those in the $50+$ age group disclosed their HIV status less frequently to nurses, lovers/ partners, HIV-negative friends, neighbors, casual friends, church members, dentists, and mental health clinicians.

\section{Factors associated with stigma and disclosure}

While older age may not emerge as significant factors related to disclosure and stigma, the interrelation of stigma, disclosure and other factors among older adults is never the less important to analyze. A bivariate correlation analysis was conducted on sociodemographic, health and social support factors thought to influence stigma and/or disclosure. The correlation matrix shown in Table 3 provides an overview of these findings.

Disclosure was significantly and positively correlated with time since first HIV diagnosis $(r=0.412 ; p<0.01)$, the use of HIV-related services $(r=0.371 ; p<0.01)$, having a confidant to talk to $(r=0.465 ; p<0.01)$ and negatively correlated with being African American $(r=$ $-0.388 ; p<0.01)$ and being exposed to HIV through heterosexual contact $(r=-0.233$; $p<$ 0.05). Higher stigma scores was positively associated with being African American $(r=$

Table 3. Bivariate Correlations Between Disclosure and Personal Factors

\begin{tabular}{|c|c|c|c|c|c|c|c|c|c|c|c|}
\hline & 1 & 2 & 3 & 4 & 5 & 6 & 7 & 8 & 9 & 10 & 11 \\
\hline Disclosure (1) & 1.00 & & & & & & & & & & \\
\hline Stigma (2) & -0.189 & 1.00 & & & & & & & & & \\
\hline $\begin{array}{l}\text { Time 1st } \\
\text { Dx (3) }\end{array}$ & $0.412^{* *}$ & -0.138 & 1.00 & & & & & & & & \\
\hline Age (4) & -0.056 & -0.119 & -0.066 & 1.00 & & & & & & & \\
\hline Education (5) & 0.167 & -0.035 & 0.106 & $0.239^{*}$ & 1.00 & & & & & & \\
\hline Income (6) & -0.063 & -0.148 & -0.022 & $0.321^{* *}$ & $0.292^{* *}$ & 1.00 & & & & & \\
\hline Hetero (7) & $-0.233^{*}$ & 0.186 & -0.115 & 0.004 & -0.134 & 0.072 & 1.00 & & & & \\
\hline $\begin{array}{l}\text { HIV services } \\
\text { (8) }\end{array}$ & $0.371^{* *}$ & 0.207 & $0.288^{* *}$ & -0.141 & 0.013 & -0.197 & -0.071 & 1.00 & & & \\
\hline Ethnicity (9) & $-0.388^{* *}$ & $0.233^{*}$ & -0.155 & -0.057 & -0.092 & -0.124 & $0.320^{* *}$ & -0.194 & 1.00 & & \\
\hline $\begin{array}{l}\text { Confidant } \\
\text { (10) }\end{array}$ & $0.465^{* *}$ & $-0.309^{* *}$ & 0.142 & -0.001 & 0.073 & 0.112 & -0.240 & 0.044 & $-0.361^{* *}$ & 1.00 & \\
\hline Help (11) & $0.265^{*}$ & $-0.286^{* *}$ & 0.019 & -0.057 & $0.216^{*}$ & $0.244^{*}$ & -0.196 & 0.057 & $-0.350^{* *}$ & $0.704^{* *}$ & 1.00 \\
\hline
\end{tabular}

${ }^{*} p<0.05 ;{ }^{* *} p<0.01$. 
0.233; $p<0.05)$ and negatively associated with social support in the forms of having a confidant $(r=-0.309 ; p<0.01)$ and having someone you can call on for help $(r=-0.286 ; p<$ 0.01). Age did not emerge in this analysis as significant with either stigma or disclosure and was only significantly correlated with greater levels of education $(r=0.239 ; p<0.05)$ and income $(r=0.321 ; p<0.01)$.

\section{Mulitvariate analysis}

In order to examine how sociodemograhic factors, health factors, and social support/formal service use influence stigma and disclosure, two hierarchical regression analyses were performed. Independent variables were entered into the models in three steps; sociodemographic factors including age, ethnicity, gender, heterosexual exposure, education and employment were entered first. The second block included time since first HIV diagnosis, followed by social support variables including receiving help (instrumental social support), having a confidant (affective social support), and use of formal HIV services. The results of two regressions are given in Table 4.

In examining disclosure as a dependent variable, ethnicity (being African American) was initially found to be significantly associated with less disclosure. However, after all variables were entered into the model, significance was not maintained. In the final model, time since diagnosis, using formal HIV services and the availability of a confidant was significantly associated with increased disclosure of HIV status. Each step contributed significantly to the overall $R^{2}$, ultimately accounting for $48.4 \%$ of the total variance for disclosure. With regards to stigma as the dependent variable, the mode was substantially less predictive. While being African American was initially found to be significant, in the final model, only the number of HIV services used was significantly associated with stigma, accounting for only $21.6 \%$ of the variance.

\section{DISCUSSION}

The purpose of this study was to contribute to the understanding of the role of age in disclosure and HIV-related stigma. Limited evidence has suggested that older adults experience greater stigma and disclose HIV status to fewer individuals than their younger counterpart.

While the findings of this study underscore the substantial presence of stigma in the lives of these subjects, there was no support for the position that older adults experience greater stigma than younger persons. What is important from the standpoint of advocacy and social change is that large proportions of these individuals, regardless of age, continue to ex-

Table 4. Standardized Regression Coefficients and Significance LeVels for Disclosure and Stigma

\begin{tabular}{|c|c|c|c|c|c|c|c|c|c|c|c|c|}
\hline \multirow{3}{*}{ Variable } & \multicolumn{6}{|c|}{ Disclosure of HIV a } & \multicolumn{6}{|c|}{ HIV Relatd Stigma } \\
\hline & \multicolumn{2}{|c|}{ Model 1} & \multicolumn{2}{|c|}{ Model 2} & \multicolumn{2}{|c|}{ Model 3} & \multicolumn{2}{|c|}{ Model 1} & \multicolumn{2}{|c|}{ Model 2} & \multicolumn{2}{|c|}{ Model 3} \\
\hline & $\beta$ & Sig. & $\beta$ & Sig. & $\beta$ & Sig. & $\beta$ & Sig. & $\beta$ & Sig. & $\beta$ & Sig. \\
\hline African American & -0.351 & 0.002 & -0.310 & 0.004 & -0.151 & 0.126 & 0.255 & 0.031 & 0.242 & 0.041 & 0.203 & 0.110 \\
\hline $\begin{array}{l}\text { Time since first } \\
\text { HIV diagnosis }\end{array}$ & & & 0.378 & 0.000 & 0.264 & 0.006 & & & -0.111 & 0.344 & -0.153 & 0.224 \\
\hline HIV services used & & & & & 0.247 & 0.012 & & & & & 0.337 & 0.009 \\
\hline $\begin{array}{l}\text { Confidant (affective } \\
\text { support) }\end{array}$ & & & & & 0.554 & 0.000 & & & & & 0.026 & 0.890 \\
\hline $\begin{array}{l}\text { Receives help } \\
\text { (instrumental } \\
\text { support) }\end{array}$ & & & & & -0.188 & 0.142 & & & & & -0.210 & 0.218 \\
\hline
\end{tabular}

${ }^{\mathrm{a}} \mathrm{R}^{2}$ for Step $1=0.123(p=0.003)$; Step $2 \Delta \mathrm{R}^{2}=0.142(p=0.000)$; Step $3 \Delta \mathrm{R}^{2}=0.219(p=0.000)$. Total Model $\mathrm{R}^{2}=0.484$

${ }^{\mathrm{b}} \mathrm{R}^{2}$ for Step $1=0.065(p=0.031)$; Step $2 \Delta \mathrm{R}^{2}=0.012(p=0.344)$; Step $3 \Delta \mathrm{R}^{2}=0.138(p=0.059)$. Total Model $\mathrm{R}^{2}=0.216$. 
perience shame, avoidance, the real or perceived loss of friends, and the sense that people are uncomfortable being around them due to their HIV disease. These findings reinforce the statements from UNAIDS ${ }^{1}$ concerning how pervasive HIV stigma continues to be.

With regard to disclosure patterns, the findings are consistent with other researchers such as Nokes and Shehan, suggesting a pattern of less disclosure among older adults. This pattern, however, rarely reached statistical significance in this study. While disclosure is often thought of as closely tied to stigma and used by some as a means of stigma management, these finding suggest little associated between these two constructs. Stigma and disclosure was not significantly associated with each other at the bivariate level, and the regression analysis suggested substantially different predictive factors for the two dependent variables. Having a confidant, or affective social support, using formal HIV services and greater amounts of time since diagnosis were important markers for disclosure.

These findings would tend to support the idea of consequence theory as presented by Serovich and Mosack. ${ }^{14}$ This approach suggests that disclosure is determined not solely by disease progression, but rather includes an analysis of the positive and negative consequences of action. The social, physical, psychological, and emotional dividends are weighed against the negative emotional consequences of disclosure. ${ }^{35}$ For example, in this sample, the need to disclose one's HIV status in order to receive formal support through the HIV service network may be considered worthwhile. Similarly, having a confidant may provide the affective support needed to cope with any negative ramifications to disclosure.

This study has various limitations that much be acknowledged. First, the sample was purposive and nonrandomized. Additionally, all respondents were clients of an ASO. These two factors suggest the possibility of sampling bias and that all subjects would be connected to some level of support and advocacy through the ASO. As all subjects were from the pacific northwest, generalizations outside of the region cannot be made.
The study does, however, provide a focused comparison of stigma, and disclosure patterns between younger and older adults, which was the original purpose of the research. Further research, including a larger, more representative sample from a broader geographic area and individuals not connected to formal support may provide further insight to the relationship between age, stigma, and disclosure.

\section{ACKNOWLEDGMENTS}

This study was supported by a grant from the John A. Hartford Foundation and the Gerontological Society of America through the Geriatric Social Work Faculty Scholars Program. The assistance of Sondra Perdue, Dr. P.H., is gratefully acknowledged.

\section{REFERENCES}

1. UNAIDS. A Conceptual Framework and Basis for Action: HIV / AIDS Stigma and Discrimination. Geneva, Switzerland: UNAIDS, 2002

2. Rutledge SE, Abell N. Awareness, acceptance and action: An emerging framework for understanding AIDS stigmatizing attitudes among community leaders in Barbados. AIDS Patient Care STDs 2005;19: 186-199.

3. Goffman E. Stigma: Notes on the Management of Spoiled Identity. Englewood Cliffs, NJ: Prentice-Hall, 1963.

4. Herek GM, Mitnick L, Burris, S. Workshop report. AIDS and stigma: A conceptual framework and research agenda. AIDS Public Policy J 1998;13:36-47.

5. Bennett M J. Stigmatization: Experiences of persons with acquired immune deficiency syndrome. Issues Ment Health Nurs 1990;11:141-154.

6. Laryea M., Gien L. The impact of HIV-positive diagnosis on the individual, part 1: Stigma, rejection, and loneliness. Clin Nurs Res 1993;2:245-266.

7. Green G, Platt S. Fear and loathing in health care settings reported by people with HIV. Sociol Health Illn 1997;19:70-92.

8. Herek GM. AIDS and stigma. Am Behav Sci 1999;42: 1106-1116.

9. Crandall CS, Coleman R. AIDS-related stigmatization and the disruption of social relationships. J Soc Pers Relat 1992;9:163-177.

10. Hall BA. Overcoming stigmatization: Social and personal implications of the human immunodeficiency virus diagnosis. Arch Psychiatr Nurs 1992:VI:189-194.

11. Heckman T, Kochman A, Sikkema, K. Depressive symptoms in older adults living with HIV disease: 
Application of the chronic illness quality of life model. J Ment Health Aging 2002;8:267-279.

12. Siminoff LA, Erlen JA, Lidz CW. Stigma, AIDS and quality of nursing care: state of the science. J Adv Nurs 1991;16:262-269.

13. Swendeman DT, Comulada WS, Lee M, RotheramBorus MJ. The impact of stigma on the adjustment of young HIV+ persons [Abstract ThPeE7916]. Presented at the XIV International AIDS Conference. Barcelona, Spain: 2002.

14. Serovich J, Mosack K. Reasons for HIV disclosure or nondisclosure to casual sexual partners. AIDS Educ Prev 2003;15:70-80.

15. Serovich J. A test of two disclosure theories. AIDS Educ Prev 2001;13:355-364.

16. Landau G, York A. Keeping and disclosing a secret among people with HIV in Israel. Health Soc Work 2004;29:116-126.

17. Miller M, Neaigus A, Serner M, Godfrey C. Nobody knows but me and God. HIV infection disclosure in an African American Community [Abstract WePeE6451]. Presented at the XIV International AIDS Conference. Barcelona Spain: 2002.

18. Emlet CA. Perceptions of stigma and ageism among older adults living with HIV / AIDS. Presented at 57th Annual Scientific Meeting of the Gerontological Society of America. Washington, D.C.: November 22, 2004.

19. Shehan CL, Uphold CR, Bradshaw P, Bender J, Arce N, Bender B. To tell or not to tell: Men's disclosure of their HIV-positive status to their mothers. Fam Relat 2005;54:184-196.

20. Mack K, Ory MG. AIDS and older Americans at the end of the Twentieth century. J Acquir Immune Defic Syndr 2003;33(Suppl 2):S68-S75

21. Center for Disease Control and Prevention. Cases of HIV infection and AIDS in the United States, 2003. HIV / AIDS Surveill Rep 2005;15:1-46.

22. Zablotsky D, Kennedy M. Assessing the progress and promise of research on midlife and older adults and HIV/AIDS. In: Emlet CA, ed. HIV/AIDS and Older Adults: Challenges for Individuals, Families and Communities. New York, NY: Springer, 2004:1-20.

23. Anderson G. Providing services to elderly people with HIV. In: Aronstein DM, Thompson, BJ, eds. HIV and Social Work: A Practitioner's Guide. New York, NY: The Harrington Park Press, 1998:443-450.

24. Solomon K. Psychosocial Issues. In: Nokes KM, ed. HIV / AIDS and the Older Adult. Bristol, PA: Taylor and Francis, 1996;33-46

25. Marr J. The impact of HIV on older people: Part 2. Nurs Stand 1994;8:25-27.

26. Lavick J. Psychosocial considerations of HIV infection in the older adult. AIDS Patient Care 1994(June):127129.

27. Fear of disclosure and popular stigmas contribute to bad outcomes. AIDS Alert 2001:16:1-5.
28. Centers for Disease Control and Prevention. HIV-related knowledge and stigma-United States, 2000. MMWR 2000;49:1062-1064.

29. McCain NL, Gramling LF. Living with dying: Coping with HIV disease. Issues Ment Health Nurs 1992;13: 271-284.

30. Fortenberry JD, McFarlane M, Bleakley A. Relationships of stigma and shame to gonorrhea and HIV screening. Am J Public Health 2002;92:378-381.

31. Crandall CS, Coleman R. AIDS-related stigmatization and the disruption of social relationships. J Soc Pers Relat 1992;9:163-177.

32. Weitz R. Living with the stigma of AIDS. Qual Sociol 1990;13:23-38.

33. Lee RS, Kochman A, Sikkema KJ. Internalized stigma among people living with HIV/AIDS. AIDS Behav 2002;6:309-319.

34. Pitts M, Grierson J, Mission S. Growing older with HIV: A study of health, social and economic circumstances for people living with HIV in Australia over the age of 50 years. AIDS Patient Care STDs 2005; 19:460-465.

35. Nokes KM, Holzemer WL, Corless IB. Health-related quality of life in persons younger and older than 50 who are living with HIV/AIDS Res Aging 2000; 22:290-310.

36. Prado G, Feaster, DJ, Schwartz, SJ, Pratt, IA, Smith, L, Szapocznik, J. Religious involvement, coping, social support and psychological distress in HIV-seropositive African American mothers. AIDS Behav 2004; 8:221-235.

37. Black BP, Miles, MS. Calculating the risks and benfits of disclosure in African American women who have HIV. J Obstet Gynecol Neonatal Nurs 2002;31:688-697.

38. Holt R, Court P, Vedhara K, Nott KH, Holmes J, Snow $\mathrm{MH}$. The role of disclosure in coping with HIV infection. AIDS Care 1998;10:49-60.

39. Sowell R, Lowenstein A, Moneyham L, Demi A, Mizuno Y, Seals B. Resources, stigma and patterns of disclosure in rural women with HIV infection. Public Health Nurs 1997;14:302-312.

40. Lubben J, Gironda M. Centrality and social ties to the health and well-being of older adults. In: Berkman B, Harootyan L, eds. Social Work and Health Care in an Aging Society. New York, NY: Springer, 2003:319-345.

Address reprint requests to: Charles A. Emlet Social Work Program University of Washington, Tacoma 1900 Commerce Street Campus Box 358425 Tacoma, WA 98402

E-mail: caemlet@u.washington.edu 